* Pós-Doutorando em Direito pela Universidade de Roma II, "Tor Vergata", Doutor pela Universidade de Roma I, "La Sapienza"/ UFSC e Mestre pela PUC/ SP. Professor Adjunto da Universidade Federal de Santa Catarina (UFSC). Professor da Graduação do UNINTER. Professor Titular do Curso de Mestrado e do Doutorado em Direito da Pontifícia Universidade Católica do Paraná (PUCPR). Membro Titular da Academia Paranaense de Direito do Trabalho. Líder do Grupo de Pesquisa "Regulação Econômica e Atuação Empresarial". Advogado. Email: marcovillatore@ gmail.com

** Mestranda em Direito Econômico e Socioambiental na Pontifícia Universidade Católica do Paraná. Advogada e Administradora Internacional de Negócios. Especialista em Direito, Logística e Negócios Internacionais. Professora no Centro Universitário Curitiba UNICURITIBA. e-mail: michele.hastreiter@gmail.com

\section{As diretrizes da OCDE para empresas transnacionais e o direito do trabalho: a pessoa humana como prioridade na busca pelo desenvolvimento}

\author{
OECD GUIDELINES FOR MULTINATIONAL \\ ENTERPRISES AND LABOR LAW: THE HUMAN BEING \\ AS A PRIORITY ON THE DEVELOPMENT PROCESS
}

\author{
* Marco Antônio César Villatore \\ ** Michele Alessandra Hastreiter
}

Resumo: As empresas transnacionais são importantes atores da sociedade capitalista globalizada e contribuem diretamente para a promoção do desenvolvimento dos países. Sua atuação, contudo, desperta importantes preocupações, o que motivou a OCDE a editar um documento com sugestões de boas práticas a serem disseminadas pelos países signatários nestas empresas. O Brasil comprometeu-se com as Diretrizes da OCDE e, em razão disto, viu-se compelido a implementar um Ponto de Contato Nacional para que a sociedade civil possa denunciar eventuais descumprimentos das diretrizes. O Ponto tem recebido alegações de descumprimentos especialmente na esfera trabalhista e tem funcionado como um instrumento para aumentar o poder de barganha dos sindicatos em negociações coletivas - com uma participação importante em diversos conflitos, especialmente no setor bancário.

Palavras-chave: Empresas transnacionais; Direito do Trabalho; OCDE; Relações Sindicais.

Abstract: Transnational corporations are important actors in the globalized capitalist society and contribute directly to the promotion of national development. Its performance, however, arouses important concerns, which led the OECD to edit a document with suggestions of good practices to be disseminated by the signatory countries in these companies. Brazil has committed to the OECD Guidelines, and therefore, was compelled to implement a National Contact Point for civil society to report possible breaches of the guidelines. The National Contact Point has received allegations of breaches especially in labor relations and has been functioning as an instrument to increase the bargaining power of Unions in collective bargaining. It has also had an important involvement on several conflicts, especially in the financial sector.

Keywords: Transnational corporations; Labor Law; OECD; Unions relations. 


\section{INTRODUÇÃO}

As empresas transnacionais, entidades dotadas de um enorme poder econômico, são grandes atores da sociedade internacional contemporânea. Sua contribuição ao crescimento econômico é inegável, sendo capazes de dinamizar a economia e gerar recursos que, quando bem aplicados internamente, podem conduzir ao desenvolvimento econômico e social. Porém, se a sua atuação for desconectada dos propósitos de desenvolvimento social e seu poder político se manifestar em desfavor do ser humano, podem ocorrer efeitos adversos e contraproducentes à busca pelo desenvolvimento. Estes impactos negativos podem ser visualizados sobretudo no tocante aos direitos humanos e fundamentais e, também, no aspecto laboral.

No entanto, não se pode negar a essencialidade destas empresas à economia moderna. É por isto que diversas Organizações Internacionais, dentre as quais a Organização para a Cooperação e Desenvolvimento Econômico (OCDE) preocuparam-se em regulamentar suas condutas, de tal forma que sua influência e atuação seja positiva na busca pela concretização do desenvolvimento enquanto um direito humano e fundamental. As Diretrizes da OCDE para Empresas Transnacionais é um dos principais documentos neste sentido, contendo diversas recomendações que incentivam uma postura socialmente responsável por parte das empresas, com especial repercussão na esfera trabalhista.

Este trabalho se dedicará a analisar a contribuição das empresas transnacionais perante as modernas definições de desenvolvimento e como as Diretrizes da OCDE buscam incentivar as empresas neste sentido. Será objeto deste trabalho, também, o Ponto de Contato Nacional para as Diretrizes da OCDE, criado como um braço do Ministério da Fazenda após a adesão brasileira às Diretrizes e cuja atuação tem sido cada vez mais marcante no tocante à implementação das recomendações constantes no documento nas transnacionais que atuam no país.

\section{O PAPEL DAS EMPRESAS TRANSNACIONAIS NA CONCRETIZAÇÃO DO DIREITO AO DESENVOLVIMENTO}

A globalização é um processo histórico e irreversível que reflete uma transformação incessante da sociedade (HOBSBAWN, 2009, p.61), impactando as mais diversas relações sociais e jurídicas - inclusive as de natureza trabalhista. Os avanços tecnológicos, a mobilidade dos fatores de produção, o fluxo 
internacional de capital e de mão de obra são alguns dos importantes fatores que caracterizam este processo e que fazem com que um dos traços mais marcantes da economia capitalista contemporânea seja sua internacionalização. Dentro deste cenário, despontam as empresas transnacionais ${ }^{1}$, entidades "dotadas de gigantesco poderio econômico" (CRETELLA NETO, 2012, p. 743), muitas com faturamento maior do que o produto interno bruto (PIB) de alguns estados e, por isto, grandes fontes de poder na sociedade capitalista global. Para Dallegrave Neto (2000, p.59), são as empresas transnacionais "quem ditam as diretivas de unificação do mercado mundial e da política sócioeconômica, em prejuízo da soberania das nações do globo".

Não há dúvidas de que a atuação de empresas transnacionais é importante para o desenvolvimento dos países em que se inserem, mas há que se admitir que podem trazer efeitos nocivos, e sua influência nos sistemas regulatórios muitas vezes faz com que os instrumentos jurídicos afastem-se da lógica de promoção do bem estar, o que pode comprometer especialmente o Direito do Trabalho e os instrumentos de proteção do empregado. A busca por um equilíbrio entre a promoção do desenvolvimento econômico e os impactos adversos da atuação das transnacionais, em especial no tocante aos direitos dos trabalhadores é um dos grandes desafios contemporâneos, e um dos fundamentos para a criação das Diretrizes da OCDE (Organização para a Cooperação Econômica e o Desenvolvimento), que será melhor descrita a seguir. Antes disto, porém, a compreensão da contribuição inegável das transnacionais para o desenvolvimento e de seus impactos adversos, precisam ser ponderados por meio da compreensão do fenômeno do desenvolvimento como um direito humano e fundamental.

\subsection{A busca pelo desenvolvimento e a contribuição da empresa transnacional}

Os debates sobre o conceito de desenvolvimento e suas diferenças entre o mero crescimento econômico são amplamente conhecidos: o crescimento, mensurável por critérios quantitativos, e o desenvolvimento, apurável

\footnotetext{
${ }^{1}$ As empresas transnacionais podem ser definidas, conforme Cretella Neto (2012, p. 768) como a "sociedade mercantil, cuja matriz é constituída segundo as leis de determinado Estado, na qual a propriedade é distinta da gestão, que exerce controle, acionário ou contratual, sobre uma ou mais organizações, todas atuando de forma concertada, sendo a finalidade de lucro perseguida mediante atividade fabril e/ou comercial em dois ou mais países, adotando uma estratégia de negócios centralmente elaborada e supervisionada, voltada para a otimização das oportunidades oferecidas pelos mercados internos".
} 
qualitativamente e mediante critérios estruturais, são duas facetas importantes e que devem ser perseguidas pelos países em sua busca pela ampliação das condições de vida de sua população. Embora o crescimento econômico não seja por si só suficiente para atestar boas condições de vida em um país, ele é um importante meio para a obtenção do desenvolvimento que tanto se busca e anseia. É nesta perspectiva que Sen (2010, p. 16) afirma que o desenvolvimento deve ser compreendido como "um processo de expansão das liberdades reais que as pessoas desfrutam", sendo que o crescimento no Produto Interno Bruno (PIB) pode até indicar um bom meio para concretizar a expansão das liberdades, mas não é um fim em si mesmo, pois não garante, por si só, o desenvolvimento. O crescimento econômico só gera desenvolvimento quando estiver acompanhado por um sistema garantidor de direitos civis e sociais, capaz de remover as fontes de privação da liberdade, dentre as quais destaca-se a pobreza, a fome, a privação de serviços públicos e de assistência social adequados, regimes políticos totalitários, entre outros (SEN, 2010, p. 17).

A economia de mercado, e a atuação das empresas, contribuem diretamente para o crescimento econômico - embora sua contribuição para o desenvolvimento dependa muito da forma como os recursos que as empresas propiciam são aplicados e das peculiaridades e singularidades da economia que recebe o capital estrangeiro. Enquanto o investimento estrangeiro "em alguns casos pode produzir reações em cadeia em toda a economia e promover a sua modernização, em outras sociedades pode ser um simples encrave, com efeitos negativos no desenvolvimento" (RISTER, 2007, p. 14). É importante, então, que os fluxos de entrada de capital sejam usados "para fazer os investimentos que facilitem e sirvam de base para transformações estruturais" (SPENCE, 2011, P. 172); isto porque são estas transformações que conduzem ao desenvolvimento - e não o simples ingresso do capital.

As empresas transnacionais buscam investir em territórios diferentes ao de sua matriz na busca por oportunidades de mercado e vantagens comparativas em seu processo de produção e de prestação de serviços. Muitas vezes, encontram essas oportunidades nos mercados emergentes (SPENCE, 2011, p. 115). Assim, as empresas transnacionais e os investimentos que realizam nas economias em desenvolvimento, como é o caso do Brasil, podem ser um fator impulsionador da economia, por sua capacidade de lhe conceder dinamismo, gerando postos de trabalho e renda à população local, além de propiciarem desenvolvimento tecnológico e trazer novas práticas administrativas e produtivas que aumentem a eficiência do mercado receptor. Como as empresas 
transnacionais "tendem a ser mais produtivas, mais orientadas para a exportação, ter tecnologia intensiva e pagar salários mais altos do que as empresas locais" (BEVIGLIA-ZAMPETTI, FREDRIKSSON, 2007, p. 63), elas podem oferecer muitos benefícios, desde que seus investimentos sejam bem aplicados internamente, justamente na busca pela concretização do desenvolvimento.

A compreensão da dimensão humana como a dimensão central do desenvolvimento é imprescindível, desta forma, para assegurar que os objetivos de crescimento e dinamização econômica alavancados pela atuação das empresas transnacionais sejam perseguidos em conformidade com os cidadãos, e não em violação aos seus direitos fundamentais.

\section{$1.2 \mathrm{O}$ direito ao desenvolvimento como direito humano e fundamental: a indivisibilidade e a interdependência dos direitos humanos}

Modernamente, o desenvolvimento tem deixado de ser considerado como um simples objetivo a ser perseguido pelos Estados, elevando-o ao grau de direito humano e fundamental. A ideia do direito ao desenvolvimento surgiu na Carta Africana dos Direitos Humanos e dos Direitos dos Povos, sendo este o primeiro documento normativo internacional a reconhecê-lo, em 1981 (RISTER, 2007, p. 53). Posteriormente, o artigo $1^{\circ}$ da Resolução $n^{\circ}$. 41/128 da Assembléia Geral das Nações Unidas de 04 de dezembro de 1986 proclamou o direito ao desenvolvimento como um direito inalienável do homem.

A concepção do desenvolvimento como um dos direitos do homem faz com que a pessoa humana passe a ser a preocupação central do processo desenvolvimentista - deixando de ser considerada como um fator de produção para apenas auxiliar no alcance deste objetivo (RISTER, 2007, p.64). Esta percepção envolve necessariamente a adoção de indicadores de qualidade de vida à noção de desenvolvimento - refutando-se sua concepção como mero crescimento, sendo que este pode ser apenas um instrumento para a obtenção daquele, e nunca um fim em si mesmo. Afasta-se, ainda, a noção de que o desenvolvimento, em uma pretensa busca incessante pelo aumento da produtividade e da competitividade, seria incompatível com um sistema protetor dos direitos humanos. Isto porque, ao ser compreendido como um direito humano e fundamental, o direito ao desenvolvimento passa a ser compreendido em razão das características intrínsecas a estes direitos, dentre as quais destacase a indivisibilidade e a interpedendência dos direitos humanos. 
A característica da indivisibilidade dos direitos humanos acarreta no fato de que "deve ser conferida a mesma proteção jurídica a todos os direitos humanos, tendo em vista serem igualmente essenciais à dignidade da pessoa humana" (ANJOS FILHO, 2013, p.93). A interdependência, por sua vez, "deve ser entendida como a mútua dependência entre os direitos humanos, considerando que o conteúdo de uns podem se vincular ao conteúdo de outros, denotando não só interação e complementaridade, mas também que determinados direitos são desdobramentos de outros" (ANJOS FILHO, 2013, 93).

Sendo assim, percebe-se que os direitos humanos têm uma relação recíproca de complementariedade, não havendo conflitos entre direitos humanos no qual um deva prevalecer sobre o outro. O direito ao desenvolvimento, compreendido neste contexto, não pressupõe uma relativização ou um enfraquecimento aos demais direitos do homem. Conforme ensina Anjos Filho (2013, p. 94) "o direito ao desenvolvimento é um instrumento de reforço à importância dos outros direitos humanos, enfatizando a interdependência e indivisibilidade de todos eles". Neste sentido, cabe destacar a crítica de Habermas (2012, p. 16) ao liberalismo econômico e seus impactos nos direitos humanos:

Uma política como a que predominou nas últimas décadas, não apenas nos EUA e na Inglaterra, mas também no continente europeu e mesmo no mundo inteiro, que pretende ser capaz de assegurar uma vida autodeterminada aos cidadãos primariamente por meio de garantias de liberdades econômicas, destrói o equilíbrio entre as diferentes categorias de direitos fundamentais. A dignidade humana, que é a mesma em todo lugar e para cada um, fundamenta a indivisibilidade dos direitos fundamentais (HABERMAS, 2012, p.16).

Esta perspectiva é crucial para o estabelecimento de limites e diretrizes para a atuação de empresas transnacionais, especialmente no tocante a sua influência na esfera trabalhista. Os objetivos dos investidores e das pessoas muitas vezes não são coincidentes (SPENCE, 2011, p.133). Ao passo que o trabalhador anseia por melhores condições de vida e trabalho, as empresas preocupam-se com uma redução do custo que maximize o lucro - o que pode recair na inobservância de regras trabalhistas ou em pressões pela redução das garantias do trabalhador. Nesse embate, é preciso sempre ter em mente que a contribuição das empresas transnacionais ao crescimento não gera desenvolvimento por si só. 
Ao compreender-se o desenvolvimento como um direito humano e fundamental, os limites às condutas das transnacionais tornam-se mais claros: os padrões mínimos de direitos humanos são invioláveis e ceder a uma eventual pressão interna ou estrangeira para uma redução destas direitos básicos é contraproducente ao objetivo do desenvolvimento. É o que procura defender as Diretrizes da OCDE, como se verificará a seguir.

\section{AS DIRETRIZES DA OCDE E A REGULAMENTAÇÃO INTERNACIONAL DA CONDUTA DAS EMPRESAS TRANSNACIONAIS:}

As empresas transnacionais não têm personalidade jurídica de Direito Internacional, o que significa que não podem assumir obrigações internacionalmente nem possuem capacidade para figurar em grande parte dos foros destinados a solução de controvérsias internacionais. Mesmo assim, sua atuação desperta preocupação nas organizações internacionais, razão pela qual alguns instrumentos jurídicos destinados a sua regulação foram criados para tentar limitar os efeitos adversos de sua atuação na busca pelo desenvolvimento, compreendido por seus aspectos qualitativos e sua concepção enquanto direito humano e fundamental.

Dentro deste contexto, a responsabilidade social das empresas é um conceito cuja importância assume uma dimensão cada vez maior na contemporaneidade, sendo inclusive objeto de diversos acordos internacionais, recomendações criadas por organizações internacionais e, também, em políticas internas das empresas. Neste contexto, uma das iniciativas de regulamentação mais abrangentes foi elaborada em 1976, pela Organização para a Cooperação Econômica e Desenvolvimento (OCDE) que, verificando o impacto e poder crescente das empresas transnacionais na busca pelo desenvolvimento dos países, elaborou recomendações para sua atuação por meio de um documento sujeito a atualizações periódicas: as "Diretrizes da OCDE para Empresas Multinacionais". A última edição foi atualizada em 2011. O documento é uma referência no que concerne à responsabilidade social das empresas transnacionai, e estabelece padrões de conduta não obrigatórios para estas empresas, consistindo, assim, em um rol de práticas de boa governança corporativa (ALLE, 2012, p. 89). O próprio documento reconhece que algumas empresas já adotam documentos internos de boas práticas, sendo que as Diretrizes, neste contexto, seriam "expectativas compartilhadas, ponto de referência para as empresas e 
complemento e reforço para a iniciativa privada" (ALLE, 2012, p. 90). A adesão das empresas é, neste caso, voluntária, mas incentivada pelos governos que aderem ao documento - estes sim, obrigados nos termos do Direito Internacional a promovê-las entre suas empresas. O Brasil, apesar de não ser membro da OCDE, aderiu às Diretrizes por meio de troca de notas, assumindo, a partir de 27 de junho de 2000, o compromisso de implementá-la.

O conteúdo das Diretrizes é bastante amplo, incorporando questões relativas aos direitos humanos, laborais, ambientais, regras de concorrência, entre outras. Porém, seu aspecto laboral é particularmente importante, já que não se pode falar em uma empresa socialmente responsável e promotora de desenvolvimento quando seus trabalhadores são tratados de forma precária e aviltados em seus direitos humanos. Sendo assim, alguns aspectos das diretrizes da OCDE no tocante ao direito do trabalho merecem uma abordagem em maior detalhe, como será feito a seguir - a começar pelas previsões contidas nas políticas gerais, que afetam aspectos trabalhistas e, em seguida, analisando-se as perspectivas de direitos humanos e do trabalho em maior detalhe.

\subsection{Políticas Gerais}

As políticas gerais são as recomendações iniciais para as empresas transnacionais, e estabelecem os princípios fundamentais das recomendações da OCDE que deverão ser considerados na interpretação das recomendações específicas, previstas em outros capítulos (OCDE, 2011). Tratam-se de 15 recomendações, dentre as quais, destacam-se os temas apresentados a seguir.

\subsubsection{Desenvolvimento sustentável e direitos humanos}

A OCDE recomenda que as empresas contribuam para o progresso econômico, ambiental e social dos países em que estão inseridas, buscando assim o desenvolvimento sustentável. Igualmente, determina a necessidade de se respeitar os direitos humanos internacionalmente reconhecidos e que sejam potencialmente afetados por sua atividade (OCDE, 2011). Percebese, assim, a preocupação da OCDE na busca pelo desenvolvimento compreendido como direito humano e fundamental. Deve-se recordar, como já se expôs, que a atuação das empresas não gera desenvolvimento por si 
só, e, por isto, a recomendação da OCDE engloba não só a abstenção de práticas nocivas aos direitos humanos, como também a implementação de efetivas ações voltadas a responsabilidade social e ao meio ambiente.

\subsubsection{Formação do capital humano e oportunidades de emprego}

Dentre as diretrizes da OCDE, consta a recomendação para que as transnacionais atuem de forma a contribuir para a formação do capital humano dos países, mediante geração de empregos e treinamentos que aumentem as capacidades de seus empregados (OCDE, 2011). Esta previsão é importante justamente por estabelecer que os benefícios da atividade da transnacional estão diretamente ligados à geração de emprego e ao aprimoramento profissional. Muitas vezes, as empresas deixam aos nacionais do país em que se instalam apenas os empregos subalternos, não aproveitando a mão de obra local para cargos mais altos. Como muitas vezes a empresa transnacional prejudica concorrentes nacionais e absorve seus postos de trabalho, as oportunidades de trabalho para a mão de obra nacional como um todo ficam prejudicadas (SILVEIRA, 2002, p. 54). O compromisso com a formação do capital humano serve para enfrentar este problema, além de contribuir para a qualificação da mão de obra nacional como um todo, elevando a produtividade do país que recebe o investimento externo.

\subsubsection{Tentativas de isenções de exigências regulatórias}

A influência política e econômica das transnacionais sobre o sistema jurídico contemporâneo é tão marcante que, muitas vezes, os Estados não tem a opção de não aceitar determinadas concessões em favor do capital. É neste sentido que a recomendação da OCDE recai sobre as pressões da empresa na busca por subsídios tributários indevidos, ou até mesmo, exceções na esfera trabalhista, ambiental e de direitos humanos, saúde e segurança (OCDE, 2011).

Saliente-se que a recomendação da OCDE diz respeito a buscar - ou aceitar, independentemente de ter efetivamente buscado - estas isenções, o que principalmente na esfera tributária é bastante frequente. As Diretrizes, no entanto, permitem especificamente as exceções que se justificam por razões legítimas de interesse público. Ademais, a recomendação da OCDE não é relacionada a eventuais reformas legislativas, mas sim a abster-se de buscar exceções não previstas na legislação. 


\subsubsection{Abstenção de envolvimentos inapropriados na política do país de acolhimento}

Um dos efeitos maléficos amplamente discutido no meio laboral é a pressão exercida pelas empresas transnacionais na busca pela flexibilização - ou, como preferem alguns, precarização de direitos trabalhistas. Como decorrência da globalização e da busca crescente por competitividade econômica, há um "consenso neoliberal de que o crescimento e a estabilidade econômica implicam a redução dos custos salariais, o que demanda a flexibilização das relações trabalhistas" (GUERRA, 2013, p. 492). Porém, como já se destacou em estudo anterior (HASTREITER, VILLATORE, 2012, p. 326) uma maior flexibilidade na legislação trabalhista não está relacionada a uma completa supressão de direitos.

De fato, a existência das empresas transnacionais como uma das grandes fontes de poder da contemporaneidade contribuem para que legislações excessivamente protecionistas sejam adaptadas à lógica da economia de mercado, sob pena de uma redução na competitividade econômica do país cujo sistema laboral seja marcado pela rigidez. Para Oliveira e Cunico (2010, p. 122), a flexibilização é a "adaptação às novas necessidades econômicas, haja vista que a ciência jurídica, sendo histórica, necessita ajustar-se às transformações sociais e políticas que se apresentam, sendo inconcebível que o Direito do Trabalho esteja à margem dessas mudanças".

É bem verdade que a atração de novos investimentos e de empresas transnacionais pode ser impactada negativamente pela rigidez excessiva das normas trabalhistas, o que acarreta em efeitos colaterais indesejáveis, como a criação de menos empregos. Dentro deste contexto, destaca-se o estudo de FERRETI e FUNCHAL (2011), que empiricamente verificou uma relação entre o aumento no número de investimentos recebidos e a redução na rigidez da regulação trabalhista em países como Brasil, Estados Unidos, Venezuela, Argentina, França, Uruguai e Chile. Isto porque a empresa transnacional tem a possibilidade de escolher onde instalar suas atividades em função dos menores custos de produção. Assim, a empresa internacionalizada consegue evitar as regras estatais e condicionamentos locais, considerando os diferenciais legislativos conforme uma lógica de "shopping normativo" (RAYMOND, 2011, p. 178).

A flexibilização pode ser realmente necessária para viabilização da atividade econômica empresarial competitiva, como uma consequência da 
economia global e da atuação das transnacionais, que nada mais é do que uma expressão daquela. Isto não é necessariamente negativo, desde que a flexibilização seja condizente com a busca pelo desenvolvimento. Como já se destacou, a concepção do direito ao desenvolvimento torna-o indissociável dos demais direitos humanos e fundamentais previstos nos instrumentos internacionais e na Constituição interna. É por isto que os direitos humanos devem ser os limites intransponíveis de quaisquer processo de flexibilização trabalhista.

As diretrizes da OCDE não tratam diretamente da temática da flexibilização - recomendando apenas que as empresas não busquem interferir negativamente na política nacional. Apesar disto, as Diretrizes incentivam uma postura bastante ativa das empresas nas negociações com sindicatos e entes coletivos, o que pode ser uma forma de combate à rigidez normativa que assegura a prevalência dos direitos básicos do trabalhador, protegendo-lhe, por meio da negociação coletiva, de violações aos seus direitos humanos e fundamentais

\subsection{Direitos humanos}

Dentre as diretrizes da OCDE há uma série de recomendações às transnacionais relativas aos direitos humanos. Destacam-se, dentre elas, as recomendações dispostas a seguir.

\subsubsection{Respeito aos direitos humanos}

As diretrizes são claras em afirmar que é uma obrigação dos Estados assegurar a prevalência dos direitos humanos em seu território, cabendo às empresas observar as normativas internas. No entanto, estabelecem que ainda que o Estado no qual estejam instaladas falhe na promoção dos direitos humanos, as empresas transnacionais devem observar os padrões internacionais em sua máxima extensão (OCDE, 2011).

Como já se destacou, o desenvolvimento é hoje considerado um direito humano e fundamental. Dentro deste contexto, para que a atuação das transnacionais seja compatível com o propósito do desenvolvimento, não se pode admitir violações aos direitos humanos que decorram de sua atividade direta ou indiretamente. Eventuais impactos negativos devem ser corrigidos e mitigados pela empresa responsável - ainda que não sejam diretamente responsáveis pelos impactos, sendo eles apenas uma decorrência de sua atuação. 


\subsubsection{Publicação de uma política de proteção aos direitos humanos, vinculando inclusive os parceiros comerciais}

Outra recomendação da OCDE no tocante aos direitos humanos é a adoção de uma política de proteção a estes direitos, a qual deve ser aprovada pelos níveis mais altos na hierarquia da empresa, estipulando inclusive quais as expectativas da empresa quanto aos seus parceiros comerciais (OCDE, 2011). Neste sentido, destaca-se que ao mesmo tempo em que é uma das grandes fontes de pressão para a diminuição da rigidez trabalhista de alguns países, o poder econômico das empresas transnacionais também pode ser um instrumento para disseminação de padrões mínimos de proteção da pessoa humana e do trabalhador globalmente. Isto porque a empresa transnacional deve se preocupar com sua imagem e possivelmente não deseja ser associada a comportamentos violadores dos direitos humanos, o que pode fazê-la perder mercado.

É bem verdade que algumas vezes esta influência positiva é espontânea: as exigências cada vez maiores da sociedade - e dos consumidores - pela responsabilidade social das empresas têm sido um fator crucial para a formação de uma consciência moral das pessoas jurídicas - sobretudo as de grade porte e, consequentemente, maior visibilidade. Nestes casos, como algumas vezes o processo produtivo é altamente fragmentado, as empresas transnacionais precisam assegurar, para a preservação de sua imagem perante os consumidores, a inexistência de condutas desabonadoras em cada uma das unidades produtivas - inclusive as terceirizadas.

Antigamente, a fragmentação da produção da transnacional podia, em alguns casos, ser um pretexto utilizado pelas empresas para limitar sua responsabilidade em caso de violações aos direitos trabalhistas. Como a subcontratação da produção, algumas vezes, gera unicamente vínculos contratuais empresariais entre a empresa contratada para a produção e a matriz da transnacional, a alegação de desconhecimento sobre as condições de trabalho dos empregados da subcontratada era comum. Porém, em um mundo de amplo acesso a informação como é o contemporâneo, a visibilidade que envolve a atividade dos grandes conglomerados exige uma atenção especial às filiais, fornecedoras, subcontratadas e outras empresas que compõem a cadeia produtiva da transnacional.

No entendimento de Raymond (2011, p.181), "esta especial visibilidad convierte a las empresas transnacionales en un sujeto particularmente vulnerable ante a cualquier comportamiento de los mencionados sujetos que suponga una 
violación de los estándares de tratamiento laboral considerados como elementales o básicos dentro de la sociedad actual ${ }^{2 "}$.

É por isto que a supramencionada pressão oriunda do poder econômico das transnacionais também pode ser positiva. Em um primeiro momento, a empresa que não deseja ver-se envolvida em denúncias de violações aos direitos humanos pode estabelecer políticas e regras contratuais internas, aplicáveis aos mais variados segmentos de sua cadeia produtiva - incluindo filiais e subcontratadas - estabelecendo padrões que podem até ser mais benéficos do que a legislação trabalhista do local de instalação da unidade produtiva. Além disto, também podem usar de seu poder e da pressão que são capazes de exercer internacionalmente para disseminar padrões laborais mínimos entre suas congêneres, já que empresas com menor visibilidade poderiam aproveitar o fato de estarem distantes dos holofotes para obterem vantagens comparativas às custas da mão de obra.

A recomendação da OCDE inclui, assim, a criação de políticas de preservação dos direitos humanos - disseminada inclusive entre os parceiros comerciais. Naturalmente, trata-se de uma recomendação impassível de obrigar as empresas, já que as diretrizes não possuem força obrigatória. No entanto, a sociedade civil tem um poder - contraposto ao poder das multinacionais - de denunciar amplamente as violações nos meios de comunicação e boicotar o consumo aos produtos das empresas envolvidas, o que torna mercadologicamente vantajosa a adoção destas políticas vinculando todos os elos da cadeia de produção da transnacional.

\subsubsection{Due dilligence em direitos humanos}

Uma interessante diretriz da OCDE no tocante aos direitos humanos é a recomendação para a realização de due dilligence especificamente voltada para a identificação de impactos negativos em direitos humanos por parte das empresas transnacionais. Segundo roteiro introdutório às Diretrizes da OCDE, elaborado pelo Ponto Nacional de Contato brasileiro, "due dilligence é o processo pelo qual as empresas identificam, evitam e mitigam efeitos adversos, reais e potenciais, assim como relatam a avaliação destes efeitos no processo decisório e na gestão de riscos" (PNC, 2011).

\footnotetext{
2 "Esta especial visibilidade converte as empresas transnacionais em um sujeito particularmente vulnerável a qualquer comportamento dos mencionados sujeitos que suponham uma violação aos padrões mínimos de tratamento laboral considerados elementares ou básicos na sociedade atual" (Tradução livre)
}

REVISTA DO DIREITO PÚBLICO, Londrina, v.9, n.3, p.45-70, set./dez.2014 
Embora inexista um procedimento definido para a execução da due dillingece, recomenda-se que as empresas: a) identifiquem os impactos reais e potenciais de sua atuação sobre os direitos humanos; b) tomem medidas apropriadas considerando estes impactos; c) verifiquem a resposta às medidas tomadas e c) comuniquem como estes impactos têm sido tratados (PNC, 2011).

As diretrizes, assim, incitam as empresas a adotarem uma postura próativa para enfrentar os efeitos adversos de suas condutas no tocante aos Direitos Humanos. Como já se sustentou, tal recomendação pode ser reforçada por uma postura encorajadora da sociedade civil, valorizando as empresas que adotam estas práticas em detrimento daquelas que não as adotam.

\subsection{Direitos dos trabalhadores}

Especificamente no tocante ao direito dos trabalhadores, dentre as Diretrizes da OCDE encontram-se uma série de recomendações, que devem ser observadas em conformidade com a legislação trabalhista aplicável, bem como os standards internacionais elaborados pela Organização Internacional do Trabalho (OIT). Em realidade, as Diretrizes ressalvam que é da OIT a competência para ditar os padrões trabalhistas internacionais e promover os direitos fundamentais do trabalhador (OCDE, 2011). As Diretrizes da OCDE, como um documento de adesão voluntária por parte dos empregadores transnacionais, contém previsões não obrigatórias no sentido de promover a observância destes padrões internacionais estabelecidos pela OIT - atuando em paralelo com suas disposições, e não em conflito com elas.

Dentre as previsões da OCDE quanto ao Direito do Trabalho, destacamse os seguintes aspectos.

\subsubsection{Direito dos trabalhadores a serem representados por sindicatos e a promoção efetiva de acordos coletivos}

Dentre as diretrizes da OCDE relacionadas ao Direito dos Trabalhadores, destacam-se as diversas previsões relativas a associação sindical e representação dos empregados, bem como o incentivo às negociações coletivas como forma de se adotar uma postura cooperada entre empregadores e empresas, reduzindo a rigidez das normas trabalhistas sem solapar os direitos do trabalhador. A OCDE expressamente determina que a empresa deve respeitar o direito dos trabalhadores de se sindicalizarem e elegerem seus representantes sindicais, 
bem como encoraja as empresas a engajarem-se na busca por acordos coletivos para determinar os termos e condições de emprego. Recomenda, também, que as empresas disponibilizem as informações necessárias aos sindicatos para negociações significativas, para que estes possam ter uma visão real e justa da performance da empresa e de suas necessidades nos acordos coletivos (OCDE, 2011).

Em uma das suas mais específicas previsões acerca deste assunto, a OCDE pontualmente recomenda que as empresas não se utilizem da possibilidade de transferir sua unidade produtiva para outro país como mecanismo de barganha em negociações coletivas. Isto porque a mobilidade do capital e a possibilidade, decorrente dos avanços tecnológicos cada vez mais impressionantes, de uma empresa operar nos mais longínquos lugares do mundo, traz consigo a permanente ameaça de retirada de empresas (e, consequentemente, dos empregos) de um determinado local para a instalação em outro, com menores custos sociais. Esta ameaça pode, inclusive, aumentar o poder de barganha das empresas transnacionais no tocante às decisões governamentais de caráter justrabalhista e certamente exerce peso nas negociações sindicais. É neste sentido que afirma Santin (2009, p.82):

Dotadas de poder de intervenção global e se beneficiando da mobilidade crescente dos processos de produção, essas empresas podem, facilmente, provocar a concorrência entre dois ou mais Estados ou duas ou mais regiões dentro de um mesmo Estado. Quando analisam as condições predeterminadas para localização do investimento, numa negociação visivelmente desigual, transformam as sociedades nacionais em dependências da sociedade global por imporem a sua política neoliberal.

Ocorre que, na prática, "não é tarefa fácil e isenta de custos - apesar de técnica e economicamente possível - promover a transferência física de linhas completas de produção para outros territórios" (CRETELLA NETO, 2012, p.753). Sendo assim, a mudança de local de produção é mais uma ameaça retórica do que concreta e real, e somente em casos extremados de ruptura institucional, uma empresa transnacional irá, de fato, retirar-se dos países em que opera, "até mesmo em virtude do dano causado á imagem institucional de que desfrutam junto à opinião pública. Empresas que realizam rápidas e frequentes mudanças na localização de fábricas correm o risco de ser classificadas como oportunistas e menos confiáveis, até mesmo nos países de origem" (CRETELLA NETO, 2012, p.753). 
Sendo assim, a OCDE busca incentivar a negociação entre a empresa e os sindicatos, sem que o seu poder econômico de empresa transnacional possa ser usado como forma de desequilibrar excessivamente a negociação em desfavor dos interesses do trabalhador.

\subsubsection{Eliminação do trabalho infantil e de todas as formas de trabalho forçado}

A preocupação com o trabalho infantil e forçado é uma das questões mais relevantes, e que revela uma das facetas mais cruéis da atuação de empresas que preocupam-se exclusivamente com a redução dos custos de mão de obra. Muitas vezes, a mão de obra escrava ou infantil não é empregada diretamente pelos grandes conglomerados, mas pelas menores empesas parceiras que compõem sua cadeia produtiva. Por isto, a existência de uma postura pró-ativa das empresas, por meio da instalação de políticas e pela realização de due dilligence, como já se mencionou, é também importante neste aspecto.

\subsubsection{Igualdade de oportunidade e tratamento e não discriminação entre empregados}

As Diretrizes da OCDE expressamente recomendam que as empresas sejam guiadas pelo princípio da igualdade de oportunidades e de tratamento entre os seus empregados, não discriminando-os em razão de sexo, idade, raça, cor, religião, opinião política, nacionalidade ou origem, ou qualquer outro status - inclusive orientação sexual, deficiências, gravidez, HIV-positivo, dentre outros (OCDE, 2011).

Recomenda-se, portanto, que as empresas, independentemente das sanções legais previstas no ordenamento interno, abstenham-se de discriminações indevidas entre os seus empregados com o objetivo de adotarem uma conduta socialmente responsável e compatível com o desenvolvimento.

\subsubsection{Padrão de tratamento dos trabalhadores}

A OCDE (2011) recomenda que as empresas transnacionais observem padrões de tratamento não menos favoráveis do que os praticados por outros empregadores de porte comparável no país em que estão instaladas. Inexistindo 
outros empregadores de porte comparável, a OCDE recomenda que a empresa adote a melhor política possível de remuneração, benefícios e condições de trabalho - as quais devem ser adequadas o suficiente para, pelo menos, satisfazer as necessidades básicas do trabalhador e de suas famílias. É também recomedável que a empresa adote práticas de saúde e segurança ocupacional em suas operações.

Embora seja um mecanismo de observância voluntária pelas empresas, as Diretrizes da OCDE determinam a obrigatoriedade dos países trabalharem para sua disseminação entre suas empresas. Por isto, determina a criação de um órgão de controle da observância das diretrizes, o Ponto de Contato Nacional, como será melhor explicado a seguir.

\section{ALEGAÇÕES DE INOBSERVÂNCIA APRESENTADAS AO PONTO DE CONTATO NACIONAL PARA DIRETRIZES DA OCDE}

Além das recomendações para as empresas transnacionais, um dos mais importantes aspectos das Diretrizes é a obrigatoriedade, para os países que a implementam, da criação de um Ponto de Contato Nacional (PCN). No Brasil, o Ponto de Contato Nacional foi criado por intermédio da Portaria ${ }^{\circ} 92$, de 12 de maio de 2003, do Ministério da Fazenda.

O objetivo do PCN é aumentar a eficácia da implementação das diretrizes, sendo um "mecanismo de promoção, solução de questão, desenvolvimento de atividades e partilha de experiências" (ALLE, 2012, p. 109). O PCN é também responsável por promover as Diretrizes, divulgando-as no idioma de seu país e por elaborar relatórios sobre suas atividades e atuações. A principal atribuição do PCN é, contudo, receber denúncias de violações cometidas por transnacionais aos valores e princípios preconizados pelas Diretrizes da OCDE e atuar como um mecanismo de soluções de controvérsias por meio da negociação e composição das partes envolvidas. Não sendo possível uma solução conciliada, o PCN deverá fazer um relatório recomendando o cumprimento das Diretrizes, e abordando os motivos pelos quais o acordo não foi possível (ALLE, 2012, p. 116).

Segundo o Resolução PCN n 01/2012, que dispõe sobre seu funcionamento, as Alegações de Inobservância poderão contemplar fatos ocorridos em até 12 meses da data do recebimento da Alegação, praticado por empresas transnacionais estabelecidas no Brasil e empresas brasileiras 
estabelecidas em um país que não tenha aderido as Diretrizes, e que não tenham sido objeto de processo judicial com trânsito em julgado. A existência de Reclamações contra uma empresa no PCN brasileiro pode levar a uma comunicação ao PCN da matriz da empresa, bem como à OCDE.

No Brasil, uma série de Reclamações foram interpostas por Sindicatos e entidades de proteção ao trabalhador contra empresas multinacionais, pela alegação de violação a direitos trabalhistas e, sobretudo, ao direito a greve. Os sindicatos têm, portanto, efetivamente utilizado os PCN como mais um instrumento de pressão para fazerem valer seus interesses (ALLE, 2012, p. 120), como ficará demonstrado na análise de algumas reclamações dispostas a seguir.

\subsection{Reclamação da Central Única de Trabalhadores (CUT) X BASF América do Sul}

De acordo com a Declaração de encerramento de Alegação de Inobservância (PCN, 2010), no dia 19 de abril de 2010, a Central Única dos Trabalhadores (CUT) ingressou com uma Reclamação em desfavor da multinacional alemã BASF S.A, alegando que a empresa estaria utilizando-se de uma brecha jurídica, o Interdito Proibitório, para impedir que dirigentes sindicais comparecessem a suas unidades, além de negar-se a dialogar com os representantes da categoria a respeito da demissão por justa causa de um representante eleito dos trabalhadores. Segundo a CUT, a empresa estaria descumprindo a diretriz da OCDE que tratava do respeito a representação sindical dos trabalhadores e ao empenho às negociações coletivas.

O PCN, em análise preliminar, concluiu pela pertinência das alegações com a temática abordada nas Diretrizes da OCDE e aceitou a reclamação, comunicando o fato ao PCN da matriz da empresa (na Alemanha) e à OCDE. Em resposta, a BASF S.A solicitou o arquivamento da Reclamação, uma vez que o movimento grevista havia sido encerrado naturalmente por falta de apoio dos empregados e julgado abusivo pelo Tribunal Regional do Trabalho, razão pela qual a empresa havia solicitado o Interdito Proibitório.

Na sequência, o PCN recebeu Carta da própria CUT e da Rede de Trabalhadores na BASF América do Sul, solicitando o cancelamento da reclamação realizada, tendo em vista a assinatura de uma carta de compromissos da BASF com os representantes dos trabalhadores, na qual constava a disposição da empresa para melhorar as condições de diálogo com os representantes dos 
trabalhadores. Nestes termos, o PCN concordou em encerrar a Reclamação.

\subsection{Confederação Nacional dos Trabalhadores do Ramo Financeiro (CONTRAF) X Banco ABN AMRO Real}

Segundo Relatório de Encerramento de Reclamação - Caso Banco ABN AMRO Real (PCN, 2012), em 19 de abril de 2007 foi apresentada Reclamação pela Confederação Nacional dos Trabalhadores do Ramo Financeiro (CONTRAF) contra o ABN AMRO Real, empresa transnacional holandesa. A empresa teria se recusado a discutir as reivindicações de seus trabalhadores com seus representantes sindicais e não respondido a 14 pedidos de negociação desde janeiro de 2002, sobre temas como emprego, terceirização, salário e saúde, além de ter cometido mais de 1.300 infrações aos direitos dos trabalhadores, apontadas pelo Ministério do Trabalho e do Emprego, violando standards mínimos de tratamento previstos pela legislação e pelo Direito Internacional e o direito à representação sindical.

A ABN AMRO alegou, sobretudo, que a empresa era brasileira e que, portanto, as Diretrizes da OCDE lhe eram inaplicáveis, que os fatos haviam ocorrido a mais de 12 meses e que a Reclamação não continha um foco claro nem documentos comprobatórios válidos. Afirmou, ainda, que não recusou-se a discutir e negociar com sindicatos, tendo inclusive firmado efetivos acordos coletivos de trabalho e que não teve 1.300 autos de infração, mas apenas sete e todos impugnados.

O PCN solicitou esclarecimentos a ambas as partes, porém não foi atendido e, em 2012, recebeu solicitação do Sindicato dos Bancários para o arquivamento da Reclamação tendo em vista a venda da ABN AMRO para o Banco Santander.

\subsection{Confederação Nacional dos Trabalhadores do Ramo Financeiro (CONTRAF) X Unibanco}

De acordo com o Relatório de Encerramento de Reclamação - Caso Unibanco (PCN, 2012), em 07 de março de 2007 foi interposta Reclamação formulada pela Confederação Nacional dos Trabalhadores do Ramo Financeiro (CONTRAF) contra o Unibanco, empresa brasileira com operações internacionais. Esta Reclamação difere, portanto, das demais porque é movida contra corporação transnacional brasileira, por sua atuação no Paraguai, país 
que não é signatário das Diretrizes da OCDE. Neste caso, o PCN brasileiro teria o papel de promover as boas práticas previstas na diretriz em suas empresas internacionalizadas - conforme expressa previsão da Resolução PCN n ${ }^{\circ}$ 01/ 2012, em seu artigo $2^{\circ}$.

AConfederação Nacional dos Trabalhadores do Ramo Financeiro interpôs a Reclamação sob a alegação de que empregada com estabilidade sindical e grávida havia sido despedida, o que violaria as disposições voltadas ao respeito à representação sindical constantes nas Diretrizes da OCDE. Aceita a Reclamação, o PCN solicitou resposta ao banco, que informou que a empregada não gozava de estabilidade sindical perante as leis do Paraguai e que a empresa desconhecia sua condição de gestante. Informou, ainda, que haveria ação trabalhista em andamento no Paraguai, a qual não havia sido julgada.

Em 2012, foi solicitado o arquivamento da Reclamação em virtude de um acordo realizado entre as partes.

\subsection{Sindicato dos Bancários de São Paulo, Osasco e Região X Itaú Unibanco S.A.}

De acordo com a Declaração de Encerramento da Alegação de Inobservância PCN n01/2012, em 06 de dezembro de 2011 o Sindicato dos Bancários de São Paulo, Osasco e Região teria ingressado com uma Alegação de Inobservância contra o Itaú Unibanco S.A, alegando que a empresa estaria realizando demissões em massa motivadas por sua recente fusão e que estaria priorizando empregados com idade avançada e mais próximos da aposentadoria, os quais teriam maiores dificuldades para se realocarem no mercado de trabalho.

Após o recebimento das alegações, o Itaú alegou que elas seriam infundadas, não sendo verdadeira a ocorrência de demissões em massa comprovando um maior número de contratações do que de desligamentos no período. Afirmou que tampouco havia uma prioridade na escolha dos empregados em idade avançada para serem demitidos.

O PCN realizou, em fevereiro de 2013, uma reunião de mediação entre o Sindicato e o Banco, no qual o Sindicato pleiteou o fornecimento de informações sobre o perfil dos empregados demitidos, a realização de negociações antes das demissões e a criação de um banco de talentos para realocação de empregados demitidos, além de um compromisso da empresa em não dispensar empregados prestes a adquirir estabilidade, em tratamento médico ou portadores de deficiência. 
A empresa, por sua vez, afirmou que as informações que poderiam ter sido fornecidas ao Sindicato já haviam sido entregues - sendo que dados mais detalhados seriam confidenciais. Além disto, informou que realiza constantemente diálogos com o Sindicato e processos de realocação no caso das demissões, inclusive aquelas motivadas por sobreposições quando da fusão entre as empresas (Itaú e Unibanco). Afirmou ainda que o Banco respeita a lei no tocante aos critérios para a demissão, inexistindo qualquer possibilidade de acordo.

Assim, o PCN encerrou a Alegação fazendo uma série de recomendações à empresa, dentre as quais destaca-se o fornecimento de informações aos representates sindicais das empresas, o aumento do diálogo, a não-discriminaçao no momento da dispensa, contratação, atribuição de trabalho ou remuneração e benefícios, entre outras. As recomendações não vinculam a empresa, mas são um instrumento de pressão para compeli-la a engajar-se em boas práticas trabalhistas. Apesar da inexistência de uma sanção ou instrumento coercitivo similar, percebe-se, com base na análise dos casos, que o PCN tem sido utilizado pelos representantes de trabalhadores como forma de elevar seu poder de negociação em face das transnacionais. Embora ainda pouco divulgado, a participação ativa do PCN sobretudo no setor bancário é notória. O fato das comunicações serem encaminhadas para os PCN das matrizes elevam a pressão sobre os diretores nacionais, que, assim, se encontram impedidos de manter os conflitos com trabalhadores locais distantes da atividade de sua matriz.

Além disto, a divulgação dos relatórios no site da $\mathrm{PCN}$ pode ser um instrumento para aumentar o engajamento da sociedade civil na busca pela responsabilidade social das corporações transnacionais. Se ampliada também para outros setores, a atuação do PCN pode tornar-se um instrumento importante na promoção de uma postura compatível com as Diretrizes da OCDE por parte das transnacionais instaladas no Brasil.

\section{CONSIDERAÇÕES FINAIS}

A compreensão do desenvolvimento como um direito humano torna-o indissociável dos demais direitos humanos e fundamentais, inclusive no que concerne aos direitos laborais. Neste sentido, para que as empresas transnacionais - atores de indiscutível relevância no cenário econômico contemporâneo - possam efetivamente contribuir para o desenvolvimento, é preciso que atentem aos parâmetros de direitos dos trabalhadores preconizados 
internacionalmente, como asseveram uma série de documentos criados por organizações internacionais para abordar a temática. Dentre estes documentos, destacam-se as Diretrizes da OCDE para Empresas Transnacionais, por sua abrangência nos temas abordados, por sua preocupação em mitigar os efeitos adversos da atuação das transnacionais e pelos mecanismos previstos para sua implementação nos países signatários.

Dentre as recomendações da OCDE no tocante ao direito do trabalho, destaca-se o incentivo para as negociações coletivas e para os acordos com os sindicatos. A importância de uma postura engajada das transnacionais nas negociações com estes órgãos é essencial para assegurar uma adequada consideração dos interesses dos trabalhadores nas decisões organizacionais que impactam nas condições de emprego. Neste sentido, há que se destacar o papel dos Pontos de Contato Nacional, que servem como um instrumento do país signatário para incentivar a aplicação das Diretrizes que, embora não sejam obrigatórias para as empresas, representam um importante compromisso de responsabilidade social.

Embora pouco divulgado, o Ponto de Contato Nacional já teve participação importante em algumas reclamações promovidas por entes coletivos - como Sindicatos e Confederações de Trabalhadores. O fato do Ponto de Contato Nacional reportar as alegações recebidas à OCDE e ao Ponto de Contato do país da matriz da empresa que recebeu a alegação, além de publicar relatórios contendo detalhes sobre a reclamação realizada, faz com que eventuais descumprimentos das Diretrizes pelas empresas ganhem visibilidade interna e internacionalmente. Em um contexto em que a sociedade civil está cada vez mais engajada em fiscalizar as empresas sob uma perspectiva de responsabilidade social, o papel dos Pontos de Contato Nacionais como fiscalizadores do cumprimento das Diretrizes se amplia: de meras recomendações sem coercitividade à conduta adequada das empresas para um instrumento de pressão - inclusive, mercadológica - para que ela se adeque aos padrões internacionais de respeito aos direitos humanos e dos trabalhadores, amplificando a contribuição das transnacionais para o desenvolvimento econômico e social.

Não há dúvidas de que o caminho para o desenvolvimento é, atualmente, indissociável das empresas transnacionais. Porém, seu porte econômico - com faturamento maior do que o PIB de países inteiros - , seu poder político, sua importância enquanto membro da sociedade internacional, e sua presença cada vez mais constante na vida das pessoas, obriga-lhe a preocupar-se com algo mais do que o lucro de seus acionistas. É esta percepção que tem impulsionado- 
as, algumas vezes até mesmo espontaneamente, a serem socialmente responsáveis. A existência de mecanismos para incentivar e promover isto por meio dos governos, de Organizações Internacionais e da sociedade civil parece ser um caminho para uma conciliação - ou ao menos uma redução de tensões - no eterno conflito entre os interesses do trabalhador e do capital.

\section{REFERÊNCIAS}

ALLE, Saulo Stefanone. Linhas diretrizes da OCDE para as empresas multinacionais e sua implementação no Brasil. Dissertação (Mestrado). Faculdade de Direito. Universidade de São Paulo, 2012.

BEVIGLIA-ZAMPETTI, Américo; FREDRIKSSON, Torborn. A dimensão do desenvolvimento nas negociações de investimento. In: AMARAL JÚNIOR, Alberto. SANCHEZ, Michelle Ratton. Regulamentação

Internacional dos Investimentos: algumas lições para o Brasil. São Paulo: Aduaneiras, 2007.

CRETElla NETO, José. Curso de Direito Internacional Econômico. São Paulo: Saraiva, 2012.

DALLEGRAVE NETO, José Affonso. Transformações das relações de trabalho à luz do neoliberalismo. In: DALLEGRAVE NETO, José Affonso; COUTINHO, Aldacy Rachid. Transformações do Direito do Trabalho. Curitiba: Juruá, 2000.

DAVIS, K. E.; TREBILCOCK, M. J. A relação entre Direito e Desenvolvimento: otimistas verus céticos. Revista Direito GV. São Paulo, ano 5, n.1, p. 217-268. Jan-Jun: 2009.

FERRETTI, R.; FUNCHAL, B. O Efeito da Regulação trabalhista e tributária nos investimentos no Brasil. Revista Administração Mackenzie. v. 12. N. 4. Disponível em:http://www.scielo.br/scielo.php?pid=S167869712011000400006\&script=sci_arttext. Acesso em 08 de maio de 2013.

GUERRA, Sidney. Curso de Direito Internacional Público. São Paulo: Saraiva, 2013. 
HABERMAS, Jürgen. Sobre a Constituição da Europa. São Paulo: Ed. Unesp, 2012.

HASTREITER, Michele A. VILLATORE, Marco Antônio C. O fluxo de capital e de mão de obra na economia global: a relação entre a mobilidade dos fatores produtivos e a legislação trabalhista. Revista Opinião Jurídica. Ano X - n. 14 - 2012. Disponível em: http://www.faculdadechristus.com.br/ index.php?option=com_flippingbook\&view=book\&id=55:revista-opiniaojuridica-mo-14\&catid=3:revista-opiniao-juridica. Acesso em 04/11/2013.

HOBSBAWN, Eric. O novo século: entrevista a Antonio Polito. São Paulo: Companhia de Bolso, 2009.

LIMA, Firmino Alves. Discriminação nas relações de trabalho. In: THOME, Candy Florencio. SCHWARZ, Rodrigo Garcia. (Org). Direito Individual do Trabalho.Rio de Janeiro: Elsevier, 2011.

OCDE. OECD Guidelines for Multinational Enterprises - 2011 Edition. Disponível em: http://www.oecd.org/daf/inv/mne/48004323.pdf. Acesso em 10/11/2013.

OIT (Organização Internacional do Trabalho). Declaração Tripartite de Princípios sobre empresas multinacionais e política social. Disponível em: http://www.oitbrasil.org.br/sites/default/files/topic/employment/pub/ decl_tripartite_multi_240.pdf. Acesso em: 07/11/2013.

OLIVEIRA, Lourival José; CUNICO, Dayane Souza. Os limites da flexibilização do Direito do Trabalho sob uma perspectiva constitucional. Revista da SJRJ. Rio de Janeiro, n.27, p.119-138, 2010. Disponível em: http://www4.jfrj.jus.br/seer/index.php/revista_sjrj/article/viewFile/123/126. Acesso em 04/11/2013.

PONTO DE CONTATO NACIONAL (PCN). AS DIRETRIZES DA OCDE PARA AS EMPRESAS MULTINACIONAIS (atualizadas em 2011): Roteiro Introdutório. Disponível em: http://www1.fazenda.gov.br/sain/ $\mathrm{pcn} / \mathrm{PCN} /$ Roteiro\%20Introdut $\% \mathrm{C} 3 \% \mathrm{~B} 3$ rio $\% 20 \% \mathrm{C} 3 \% \mathrm{~A} 0 \mathrm{~s} \% 20 \mathrm{Diretrizes} \% 2$ 0da\%20OCDE.pdf. Acesso em: 06/11/2013. 
PONTO DE CONTATO NACIONAL (PCN). Declaração de Encerramento de Alegação de Inobservância. Disponível em: http:// www1.fazenda.gov.br/sain/pcn/PCN/Relatorio\%20Final\%20de\%20Alega\% E7\%E3o\%20n\%BA\%2003-2010.pdf. Acesso em: 07/11/2013.

PONTO DE CONTATO NACIONAL (PCN). Relatório de Encerramento de Reclamação - Caso Unibanco. Disponível em: http:// www1.fazenda.gov.br/sain/pcn/PCN/reclamacao_05_2007.pdf. Acesso em: 07/11/2013.

PONTO DE CONTATO NACIONAL (PCN). Relatório de Encerramento de Reclamação - Caso ABN AMRO. Disponível em: http://www1.fazenda.gov.br/sain/pcn/PCN/ Relat\%C3\%B3rio\%20de\%20Encerramento\%20de\%20Reclama\% C3\%A7\%C3\%A3o\%20-\%20ABN\%20AMRO\%20Real.pdf. Acesso em: $08 / 11 / 2013$.

PONTO DE CONTATO NACIONAL (PCN). Declaração de Encerramento - Alegação de Inobservância PCN $\mathbf{n}^{\circ}$ 1/2012.

Disponível em: http://www1.fazenda.gov.br/sain/pcn/PCN/ Declara\%C3\%A7\%C3\%A3o\%20de\%20Encerramento\%20-\%20Alega\% C3\%A7\%C3\%A3o\%20n\%C2\%BA1\%202012.pdf. Acesso em: 08/11/2013.

RAYMOND, Wilfredo Sanguineti. La tutela de los derechos fundamentales del trabajo en las cadenas de producción de las empresas multinacionales. In: THOME, Candy Florencio. SCHWARZ, Rodrigo Garcia. (Org). Direito Individual do Trabalho.Rio de Janeiro: Elsevier, 2011.

SANTIN, Janaína Rigo. As novas fontes de poder no mundo globalizado e crise de efetividade do Direito. Revista da SJRJ, Rio de Janeiro, n.25, p.7992, 2009. Disponível em: http://www4.jfrj.jus.br/seer/index.php/revista_sjrj/ article/viewFile/3/2. Acesso em: 03/11/2013.

SEGOVIA, Amparo Merino. Responsabilidad Social Corporativa: su dimensión laboral. In: THOME, Candy Florencio. SCHWARZ, Rodrigo Garcia. (Org). Direito Individual do Trabalho.Rio de Janeiro: Elsevier, 2011. 
SEN, Amartya. Desenvolvimento como liberdade. São Paulo: Companhia das Letras, 2010.

SILVEIRA, Eduardo Teixeira. A disciplina jurídica do investimento estrangeiro no Brasil e no Direito Internacional. São Paulo: Editora Juarez de Oliveira, 2002.

SPENCE, Michael. Os desafios do futuro da economia: o crescimento econômico mundial nos países emergentes e desenvolvidos. Rio de Janeiro: Elsevier, 2011.

TRAVIESSO, J. A. Los Derechos Humanos em la Constituición de la República Argentina. Editorial Buenos Aires: Argentina, 2000.

\section{UNCTAD. Draft United Nations Code of Conduct on Transnational} Corporations. (1983 version). Disponível em: http://unctad.org/sections/ dite/iia/docs/Compendium/en/13\%20volume\%201.pdf. Acesso em: 05/11/ 2013.

VARELLA, M. D. Internacionalização do Direito: direito internacional, globalização e complexidade. Brasília:UniCEUB, 2013.

WINTER, Luís Alexandre Carta. WACHOWICZ, Marcos. Empresa transnacional como fator de desenvolvimento e integração regional para a América Latina. Anais do CONPEDI - Salvador-BA. Disponível em: http://www.conpedi.org.br/anais_salvador.html. Acesso em: 04/11/2013.

Artigo recebido em: 24/09/2014 Aprovado para publicação em: 21/11/2014

Como citar: HASTREITER, Michele Alessandra. VILLATORE, Marco Antônio César. As diretrizes da OCDE para empresas transnacionais e o Direito do Trabalho: a pessoa humana como prioridade na busca pelo desenvolvimento. Revista do Direito Público. Londrina, v.9, n.3, p.45-70, set./ dez.2014. DOI: 10.5433/1980-511X.2014v9n3p45. 